\title{
Experimental Research of Mechanics and Microscopic on Nansha Soft Soil Reinforced with Cement-based Curing Agent
}

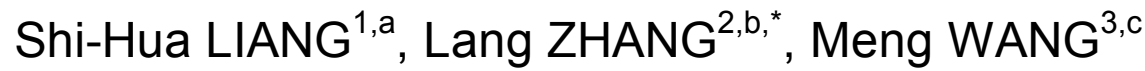 \\ ${ }^{1,2,3}$ Faculty of Civil and Transportation Engineering, Guangdong University of Technology, \\ Guangzhou, Guangdong ,500006, P.R. China

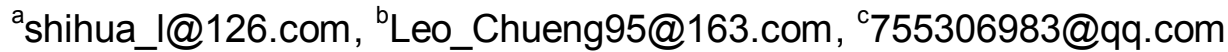 \\ ${ }^{*}$ Corresponding author
}

\begin{abstract}
Keywords: Silt, Curing Agent, Mixing Ratio, Curing Age, Mechanics Experiment, Electron Microscope Scanning.
\end{abstract}

\begin{abstract}
Based on ordinary Portland cement, in this paper, direct shear test and unconfined compression test were conducted on Nansha Guangzhou soft silt blended with admixtures such as lime or gypsum respectively to research its mechanical property and get the correlation between reinforced silt's internal friction angle(IFA), cohesion, unconfined compressive strength(UCS) and mixing ratio or age, scanning electron microscope observation(ESM) was conducted to research the different microstructure characteristics of different reinforced silt. The results show that data trending was similar to the outcome while cement was blended in merely. Mechanical parameters of the reinforced silt increase when the mixing ratio or curing age increases. But different curing agent has different influence. Lime has the best effect on long-term strength. As far as early age strength is concerned, gypsum has the best reinforcement effect and gypsum takes second place. For a certain strength requirement, gypsum can reduce the consumption of cement at a certain degree. The research result has a certain reference value for similar research and engineering.
\end{abstract}

\section{Introduction}

Most soft soil in Nansha Guangzhou is silt or silty soil with high water content who presents poor engineering characteristics such as high compressibility, low capacity, strong structural. [1,2]As a consequence, to meet the requirement of engineering it must be treated properly. Using curing agent to reinforce soft soil is one of the common methods to treat soft soil foundation in engineering. The most commonly used curing agent is cement. But the result is unsatisfactory for some soil when it reinforced with cement merely, and the consumption is high. Thus, it's a important issue to solve urgently that developing new curing agents which can apply to various soil as well as reduce the cost in the development of the technology that reinforcing soft foundation with cement-based curing agent.

Existing research shows, Stirring foundation soft soil with cement-lime slurry can demonstrate the advantages of each curing agent, improve the strength of foundation soil and reduce the consumption. [3,4] The strength of reinforced soil increases with the dosage of cement and lime increasing, with the curing age prolonging.[5] When the cement mixing ratio is $15 \%$ in silty clay, the reinforcing effect to cemented soil made by calcium hydroxide contained in the lime added is limited, nevertheless, general trend is still that with lime contain increasing, the strength of cement-lime soil increases.[6] Compared to the situation that cement is blended into merely, soil strength is doubled and consumption is more economical when both cement and industrial waste gypsum are used to reinforce the soft soil foundation. But the best gypsum mixing ratios for various soil with different characters are not the same.[7-9] Engineering practice also shows, compared to reinforced with only cement, it observably improve the strength of the foundation, broaden the application range of cement reinforcement technique and its technical, economic and environmental benefits are obvious to added gypsum into soft soil accompanied by ardealite. [10] Some scholars believe that it is inexactly to assess the result of reinforcement effect only by analyzing the macroscopic mechanical properties, in micro-level, such as the formation of ettringite must be counted for it can change the microstructure.[11] With the curing age prolonging pore filling effect in the silt reinforced by cement-lime comes more obvious, and this is the reason at micro-level why strength 
increases. [12] It is the obvious difference at micro-level such as hydration reaction degree and structure who make the macroscopical strength different between soil reinforced by cement together with gypsum or not.[13] Until now, the special research on reinforcement on soft soil in Pearl River Delta is not perfect. Based on existing results this paper studied on soft soil in Nansha Guangzhou reinforced with lime or gypsum accompanied by cement and analyzed the reinforcement effect of each curing agent together with cement.

\section{Physical and Mechanical Properties of Undisturbed Soil}

The test silt used in the research was taken from the intersection of Huanshi Road and Shuangshan Road Nansha District, Guangzhou Its basic parameters are shown in Table 1.

Tab.1 Physical Parameters of Soft Soil Used in Experiments

\begin{tabular}{|c|c|c|c|c|c|c|c|c|}
\hline $\begin{array}{c}\text { Moisture } \\
\text { content[ } \\
\omega / \%]\end{array}$ & $\begin{array}{c}\text { Density[ } \\
\rho \mathrm{g} / \\
\mathrm{cm} 3]\end{array}$ & $\begin{array}{c}\text { Dry } \\
\text { density[ } \rho \mathrm{g} / \\
\mathrm{cm} 3]\end{array}$ & $\begin{array}{c}\text { Specific } \\
\text { gravity of } \\
\text { soil } \\
\text { particle[G }\left[\mathrm{G}_{\mathrm{s}}\right]\end{array}$ & $\begin{array}{c}\text { Void } \\
\text { ratio } \\
{[\mathrm{e}]}\end{array}$ & $\begin{array}{c}\text { Liquid } \\
\text { limit[ } \omega \\
\mathrm{L} / \%]\end{array}$ & $\begin{array}{c}\text { Plastic } \\
\text { limit } \\
{\left[\omega_{\mathrm{P}}\right.} \\
/ \%]\end{array}$ & $\begin{array}{c}\text { Liquid } \\
\text { ity } \\
\text { index[ } \\
\mathrm{IL}]\end{array}$ & $\begin{array}{c}\text { Plastic } \\
\text { limit } \\
\text { index[IP/ } \\
\%]\end{array}$ \\
\hline 69.28 & 1.67 & 1.09 & 2.7 & 1.74 & 52.84 & 38.14 & 2.12 & 14.7 \\
\hline
\end{tabular}

\section{Experimental Program}

\section{Specimen Preparation}

Soil was put into a oven under the temperature between 105 to $115^{\circ} \mathrm{C}$ until its quality didn't change any more before it was mashed with a mallet. To remove impurities soil powder was filtrated with $2 \mathrm{~mm}$ sifter. After that soil powder was reserved in sealed plastic bags for test.

Direct shear test specimens were made with cutting rings of $61.8 \mathrm{~mm}$ diameter $20 \mathrm{~mm}$ high. Unconfined compression test specimens were made with three-way split formers of $39 \mathrm{~mm}$ inner diameter $80 \mathrm{~mm}$ high. Preparation method: get some dry soil powder, cement and other curing agent on a certain mixing proportion (Table 2) in a barrel and blend them adequately. Add water at the original water content and a water cement ratio of 0.5 . Then stir them until the mixture become homogeneous. Wash a three-way split former clean, paint a layer of lubricant on it inwall and put it on a piece of glass coated with a thin layer of lubricant. Then stuff the mixed soil into the former in 3-5 layers and tamp it layer by layer, plane the top layer and cover it with a piece of glass coated with a thin layer of lubricant. Put it in a plastic bag as a whole, and seal it. At last, put the specimen in a big sealing box together with the former and glass with some water on the bottom until the were used for tests on the certain curing age. The procedure of making specimens with cutting rings was similar. Additionally, a bit of mixed soil must be reserved for scanning electron microscope observation on the same curing conditions. This experiment used the following curing agents, Shijing brand cement with strength of $42.5 \mathrm{MPa}$ made in Guangzhou, lime, gypsum.

Tab. 2 Mix Proportion of Curing Agents

\begin{tabular}{|c|c|c|c|c|c|}
\hline \multirow{2}{*}{$\begin{array}{c}\text { Dosage } \\
\text { levels }\end{array}$} & \multicolumn{3}{|c|}{ Proportion } & \multicolumn{2}{c|}{ Sample quantity } \\
\cline { 2 - 6 } & $\begin{array}{c}\text { Moisture } \\
\text { content }\end{array}$ & Cement & Lime/gypsum & $\begin{array}{c}\text { Three-way } \\
\text { split formers }\end{array}$ & cutting ring \\
\hline 1 & $70 \%$ & $15 \%$ & 0 & 9 & 27 \\
\hline 2 & $70 \%$ & $15 \%$ & $1.5 \%$ & 9 & 27 \\
\hline 3 & $70 \%$ & $15 \%$ & $3 \%$ & 9 & 27 \\
\hline 4 & $70 \%$ & $15 \%$ & $4.5 \%$ & 9 & 27 \\
\hline
\end{tabular}

\section{Selected Tests}

This paper selected direct shear test, unconfined compression test and scanning electron microscope observation to support the research. The specimens made with cutting rings were used in direct shear tests 
and these tests were conducted on strain controlled direct shear tester to get reinforced soil's internal friction angle(IFA) and cohesion. Specimens made with three-way split formers were used in unconfined compression tests and these tests were conducted on LCD automatic pressure testing machine to get reinforced soil's unconfined compressive strength(UCS). The reserved a bit of soil was used in scanning electron microscope observation and these tests were conducted on scanning electron microscope model-JSM6490LV to research the reinforced soil's micro-characteristic .

\section{Experimental Data and Analysis of Data}

\section{Experimental Data of Cement Single-doped Tests and Brief Analysis}

Currently, the cement mixing ratio in cemented soil in China is between 5\% to 25\%.[14] This research selected four cement mixing ratios, $10 \%, 15 \%, 20 \%$ and $25 \%$. Test data about cemented soil on 7 days, 15 days and 28 days, are showed in Table 3.

Tab.3 Test Data of Nansha Silt Reinforced by Cement Merely

\begin{tabular}{|c|c|c|c|c|c|c|c|c|c|}
\hline Content & \multicolumn{9}{c|}{ Experimental data } \\
\hline \multirow{2}{*}{ Cement } & \multicolumn{3}{|c|}{ internal friction angle $\left[^{\circ}\right]$} & \multicolumn{3}{c|}{ Cohesion[kPa] } & \multicolumn{3}{|c|}{$\begin{array}{c}\text { unconfined compressive } \\
\text { strength[kPa }]\end{array}$} \\
\cline { 2 - 11 } & $7 \mathrm{~d}$ & $15 \mathrm{~d}$ & $28 \mathrm{~d}$ & $7 \mathrm{~d}$ & $15 \mathrm{~d}$ & $28 \mathrm{~d}$ & $7 \mathrm{~d}$ & $15 \mathrm{~d}$ & $28 \mathrm{~d}$ \\
\hline $10 \%$ & 6.32 & 7.49 & 8.31 & 28 & 49.7 & 57.73 & 240 & 255 & 270 \\
\hline $15 \%$ & 8.79 & 10.31 & 12.33 & 73.47 & 82.07 & 99.67 & 448 & 520 & 661 \\
\hline $20 \%$ & 11.89 & 15.5 & 18.41 & 91.52 & 106.7 & 123.52 & 608 & 770 & 966 \\
\hline $25 \%$ & 13.01 & 17.63 & 20.71 & 101.66 & 118.4 & 160.86 & 846 & 1310 & 1560 \\
\hline
\end{tabular}

As shown in Table 3, on the same cement mixing ratio, reinforced soil's shear strength and UCS increase with curing age increasing and they increase with mixing ratio when curing age is certain. As 28 days data, when cement mixing ratio increases from $10 \%$ to $15 \%$, the reinforced soil's IFA, cohesion and UCS increase respectively by $48.4 \%, 72.7 \%$ and $144.8 \%$. When the ratio increases from $15 \%$ to $20 \%$ the three parameters increase respectively by $49.3 \%, 23.9 \%$ and $46.1 \%$. When it increases from $20 \%$ to $25 \%$, the growths are $12.5 \%, 30.2 \%$ and $61.5 \%$. Comparison of the data above shows that the growth comes to the peak when mixing ratio increases from $10 \%$ to $15 \%$. When it comes to 7 days data, a similar result presented. Combined practical engineering, $15 \%$ was selected as the benchmark cement mixing ratio.

\section{Experimental Data of Soil Reinforced with Other Curing Agent and Cement and the Analysis}

Based on $15 \%$ cement mixing ratio and $70 \%$ water content, tests were conducted on Nansha soil reinforced with cement accompanied by lime or gypsum respectively. The experimental data on different mixing ratio at different curing age are shown as Table 3 to 5 and the data curves are shown as Fig 1 to Fig.9. As Fig.1 to Fig.9 showing, it is similar to the result of cement single-doped tests. On the same cement mixing ratio, reinforced soil's shear strength and UCS increase with curing age increasing and they increase with mixing ratio when curing age is certain.

Tab.4 Test Data of Nansha Silt Reinforced by Cement and Lime

\begin{tabular}{|c|c|c|c|c|c|c|c|c|c|}
\hline Content & \multicolumn{9}{|c|}{ Experimental data } \\
\hline \multirow{2}{*}{ Lime } & \multicolumn{2}{|c|}{ internal friction angle[॰] } & \multicolumn{3}{c|}{ Cohesion[kPa] } & \multicolumn{3}{c|}{$\begin{array}{c}\text { unconfined compressive } \\
\text { strength[kPa] }\end{array}$} \\
\cline { 2 - 10 } & $7 \mathrm{~d}$ & $15 \mathrm{~d}$ & $28 \mathrm{~d}$ & $7 \mathrm{~d}$ & $15 \mathrm{~d}$ & $28 \mathrm{~d}$ & $7 \mathrm{~d}$ & $15 \mathrm{~d}$ & $28 \mathrm{~d}$ \\
\hline 0 & 8.79 & 10.31 & 12.33 & 73.47 & 82.07 & 99.67 & 448 & 520 & 661 \\
\hline $1.5 \%$ & 10.72 & 12.27 & 14.1 & 91.81 & 100 & 109.37 & 480 & 613 & 762 \\
\hline $3 \%$ & 14.39 & 15.21 & 16.74 & 97.89 & 107.3 & 115 & 560 & 960 & 1260 \\
\hline $4.5 \%$ & 15.38 & 16.57 & 17.9 & 99.84 & 109.6 & 117.31 & 700 & 1040 & 1373 \\
\hline
\end{tabular}




\section{Experimental Data of Soil Reinforced with Cement-lime and Analysis}

Base on $15 \%$ cement mixing ratio, Nansha soil was reinforced together with lime at variable mixing ratio. Three tests were conducted to get the data shown in Table 4. And the data curves were shown as Fig1 to Fig.3.

From Table4 and Fig.1 to Fig.3, the following views can be drawn:

1. As long-term strength considered, 28 days strength, for example, when the lime mixing ratio is $1.5 \%$, compared to the experimental data of soil reinforced by cement merely, the reinforced soil's IFA, cohesion and UCS increase respectively by $14.4 \%, 9.7 \%$ and $15.3 \%$. It suggests that addition lime assists cement in reinforcing Nansha soil. When the lime mixing ratio comes to $3 \%$, compared to the experimental data of soil reinforced by cement and $1.5 \%$ lime, the growth rate of the three parameters become $18.7 \%, 5.1 \%$ and $65.4 \%$. That is a big increase. It suggests that the mixing ratio of lime would influence the reinforcement effect of cement acting on Nansha soil. But when it comes to $4.5 \%$, compared to the experimental data of soil reinforced by cement and 3\% lime, the growth rate of the three parameters become $6.9 \%, 2 \%$ and $9 \%$. The growth retards by a large margin. It suggests that, based $15 \%$ cement mixing ratio, the reinforced soil's strength increases with the lime mixing ratio increasing and the best mixing ratio of lime is $3 \%$ around. At a lime mixing ratio of $3 \%$, compared to the experimental data of soil reinforced by cement merely, the three parameters increase respectively by $35.8 \%, 15.4 \%$ and $90.6 \%$. The result is very good.

2. As early strength considered, 7 days strength, for example, when the lime mixing ratio is $3 \%$, compared to the experimental data of soil reinforced by cement merely, the reinforced soil's IFA, cohesion and UCS increase respectively by $63.7 \%, 33.2 \%$ and $25 \%$. The result is good. It suggests that addition lime assists cemented soil's early strength forming. But compared to the analysis in view 1 above, the assistance on long-term strength is much more obvious.

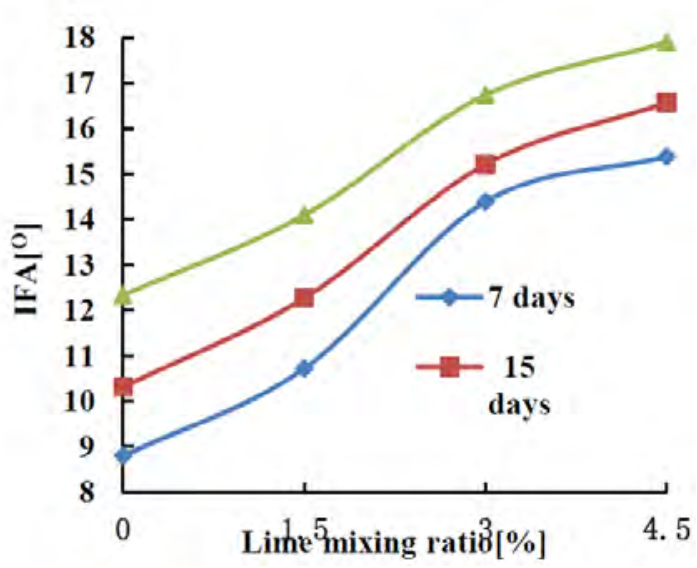

Fig.1 IFA-lime Mixing Ratio Diagram

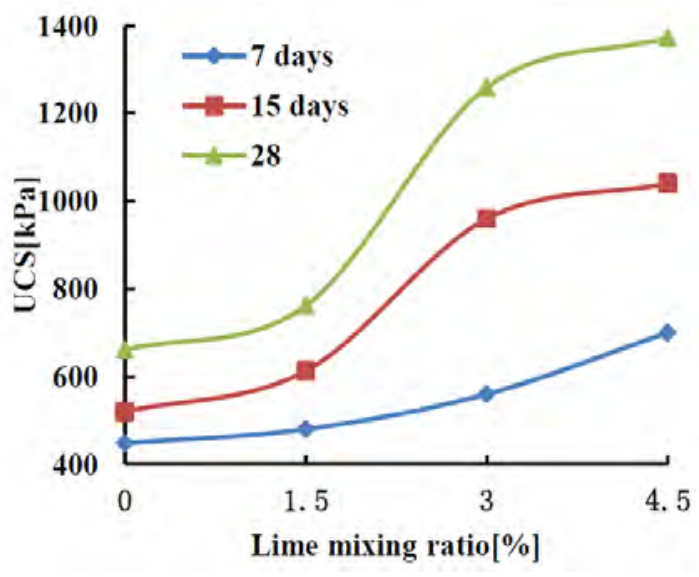

Fig.3 UCS- lime Mixing Ratio Diagram

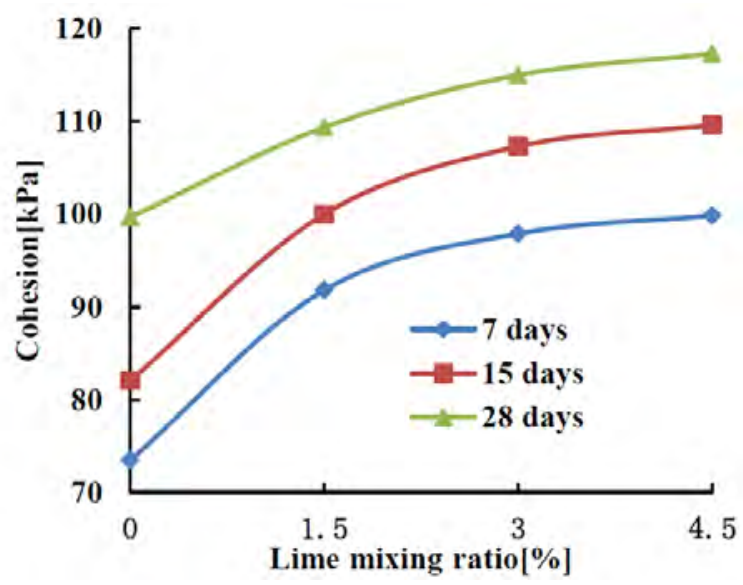

Fig.2 Cohesion-lime Mixing Ratio Diagram

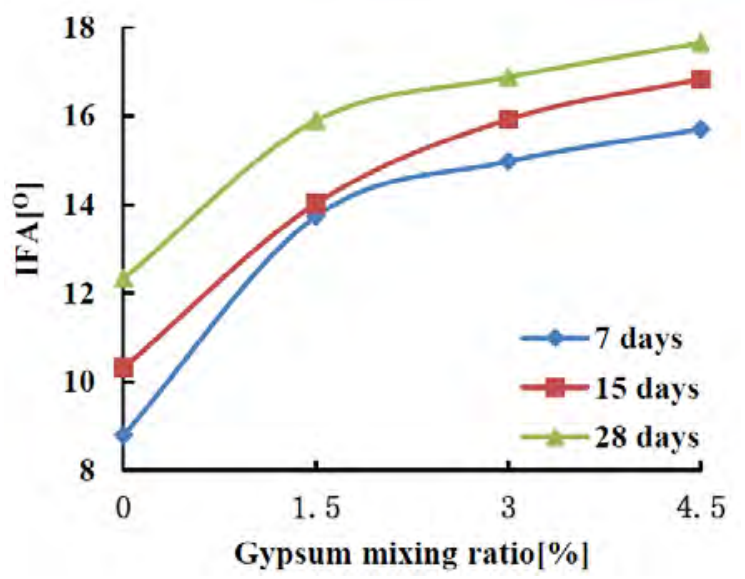

Fig.4 IFA- gypsum Mixing Ratio Diagram 


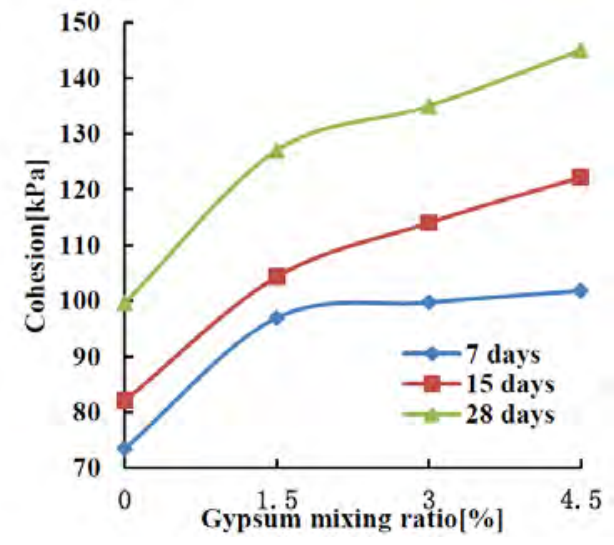

Fig.5 Cohesion- gypsum Mixing Ratio Diagram

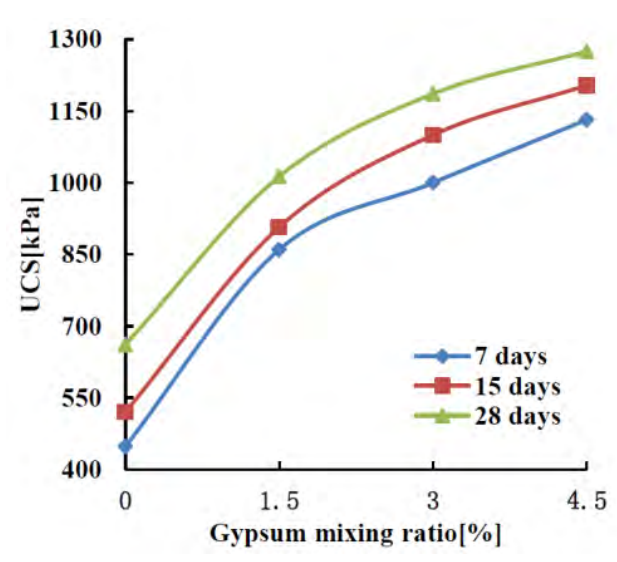

Fig.6 UCS- gypsum Mixing Ratio Diagram

\section{Experimental Data of Soil Reinforced with Cement-gypsum and the Analysis}

Base on $15 \%$ cement mixing ratio, Nansha soil was reinforced together with gypsum at variable mixing ratio. Three tests were conducted to get the data shown in Table 5. And the data curves were shown as Fig.4 to Fig.6.

Tab. 5 Test Data of Nansha Silt Reinforced by Cement and Gypsum

\begin{tabular}{|c|c|c|c|c|c|c|c|c|c|}
\hline Content & \multicolumn{9}{|c|}{ Experimental data } \\
\hline \multirow[t]{2}{*}{ Gypsum } & \multicolumn{3}{|c|}{ internal friction angle $\left[^{\circ}\right]$} & \multicolumn{3}{|c|}{ Cohesion[kPa] } & \multicolumn{3}{|c|}{$\begin{array}{c}\text { unconfined compressive } \\
\text { strength }[\mathrm{kPa}]\end{array}$} \\
\hline & $7 \mathrm{~d}$ & $15 \mathrm{~d}$ & $28 \mathrm{~d}$ & $7 \mathrm{~d}$ & $15 \mathrm{~d}$ & $28 \mathrm{~d}$ & $7 \mathrm{~d}$ & $15 \mathrm{~d}$ & $28 \mathrm{~d}$ \\
\hline 0 & 8.79 & 10.31 & 12.33 & 73.47 & 82.07 & 99.67 & 448 & 520 & 661 \\
\hline $1.5 \%$ & 13.73 & 14.02 & 15.89 & 96.95 & 104.3 & 127 & 860 & 907 & 1013 \\
\hline $3 \%$ & 14.97 & 15.92 & 16.87 & 99.7 & 114 & 135 & 1000 & 1100 & 1186 \\
\hline $4.5 \%$ & 15.7 & 16.83 & 17.65 & 101.8 & 122.21 & 145 & 1132 & 1204 & 1275 \\
\hline
\end{tabular}

From Table 5 and Fig.4 to Fig.6, the following views can be drawn:

1. As long-term strength considered, 28 days strength, for example, with similar analysis, it can be acquired that the best mixing ratio of gypsum is $1.5 \%$ around.

2. As 7 days strength considered, when gypsum mixing ratio is $1.5 \%$, compared to the experimental data of soil reinforced by cement merely, the three parameters increase respectively by $56.2 \%, 32 \%$ and $92 \%$. It suggests that addition gypsum can improve the early strength of Nansha soil reinforced by cement by a large margin.

3. When curing age is treated as the independent variable, the flowing view can be drawn. When gypsum mixing ratio is $1.5 \%$, reinforced soil's IFA, cohesion and UCS at 7 days curing age are $86.4 \%$, $76.3 \%$ and $84.9 \%$ of the homologous parameter 28 days curing age. It suggests that addition gypsum can accelerate the strength forming speed of cemented soil.

4. When the gypsum mixing ratio is $1.5 \%$ and curing age is 28 days, the reinforced soil's IFA, cohesion and UCS are $15.9^{\circ}, 127 \mathrm{kPa}$ and $1013 \mathrm{kPa}$. The three parameters are $18.4^{\circ}, 123.5$ and 966 when Nansha soil reinforced by cement merely at the mixing ratio of $20 \%$. The two group data are approximate. It suggests that for a certain strength requirement to Nansha soil, $1.5 \%$ addition gypsum can reduce the consumption of cement by a approximate rate of $25 \%$.

\section{Microscopic Construction and Brief Analysis}

Physical and mechanical performance of soil are the macroscopical manifestation of its microscopic structure. The method to reinforce soil with curing agents is to change its microcosmic structure. For future study on the reinforcement effect about curing agents, scanning electron microscope observations were conducted on undisturbed soil and reinforced soil. Based on the SEM pictures, the relationship between soil's macroscopic properties and the change of its microscopic structure was analyzed. 


\section{Microstructure Characteristics of Undisturbed Soil and Cemented Soil}

Fig.7 is the SEM picture of undisturbed soil. As shown in Fig.7, undisturbed soil is consisted by irregular schistose particles. These particles distribute optionally and form the soil's space structure. As a result, the skeleton of undisturbed soil is shaggy and porosity is high. And the link between the particles is simple touch. Fig. 8 is the SEM picture of soil reinforced by $15 \%$ cement. As shown in Fig. 8 , the schistose structure is not so obvious. Some globular, bacilliform and fibriform matter can be seen and the particles gather together as pelletizations. Reasons are as following. Fibriform matter which is produced in the reaction of $\mathrm{Ca}^{2+}$ generated in hydrolysis of cement and clay minerals attach on the particles and congeal them. Hence the soil becomes much more pyknotic and the porosity reduce and the interaction among the particles is enhanced. As a result, the strength is improved.

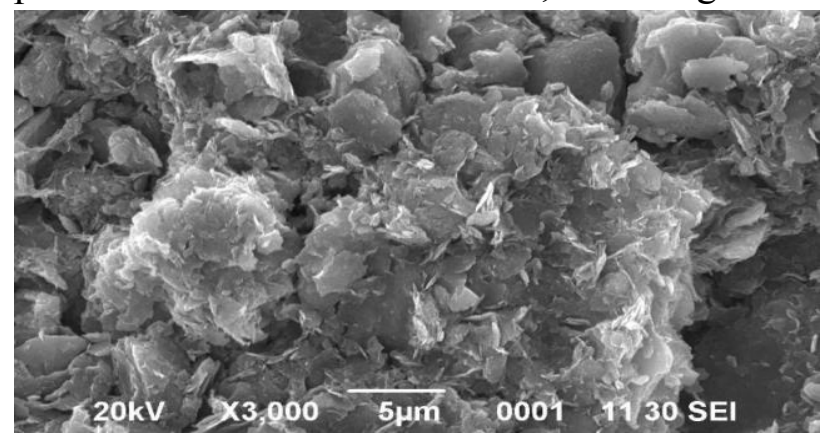

Fig.7 SEM Picture of Undisturbed Soil

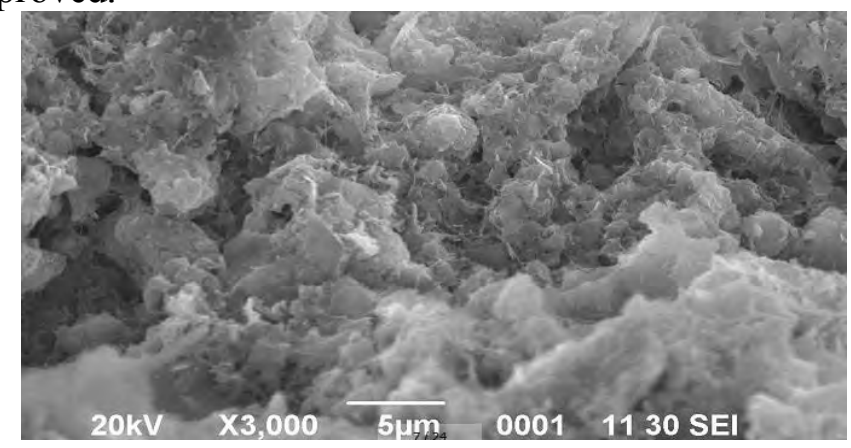

Fig. 8 SEM Picture ( $15 \%$ cement)

\section{Microstructure Characteristics of Soil Reinforced by Cement-lime}

$3 \%$ lime, for example, as shown in Fig.9, compared to Fig. 8, the same is that some globular, bacilliform and fibriform matter can be seen and particles gather together as pelletizations. The difference is that the pelletizations are bigger. Reasons are as following. Addition lime increases the content of $\mathrm{Ca}(\mathrm{OH})_{2}, \mathrm{Ca}^{2+}$ and $\mathrm{OH}^{-}$in the cemented soil at a large degree. Much more $\mathrm{Ca}^{2+}$ participates in the equivalent adsorption exchange with $\mathrm{K}^{+}$and $\mathrm{Na}^{+}$which make the adsorbed layer cover the colloid thinner and pelletizations bigger. Besides crystallization reaction of $\mathrm{Ca}(\mathrm{OH})_{2}$ produce water lattice $\left(\mathrm{Ca}(\mathrm{OH})_{2} \cdot \mathrm{nH}_{2} \mathrm{O}\right)$ which can gather together and form cocrystallization with soil particles and glue the particles.

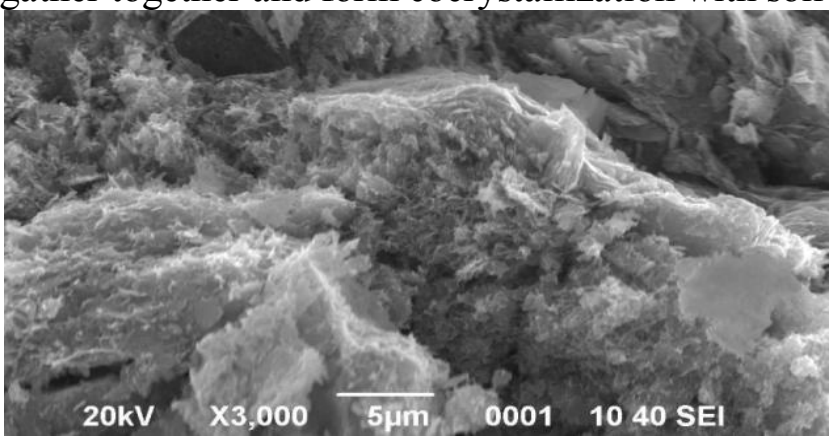

Fig. 9 SEM Picture( $3 \%$ lime)

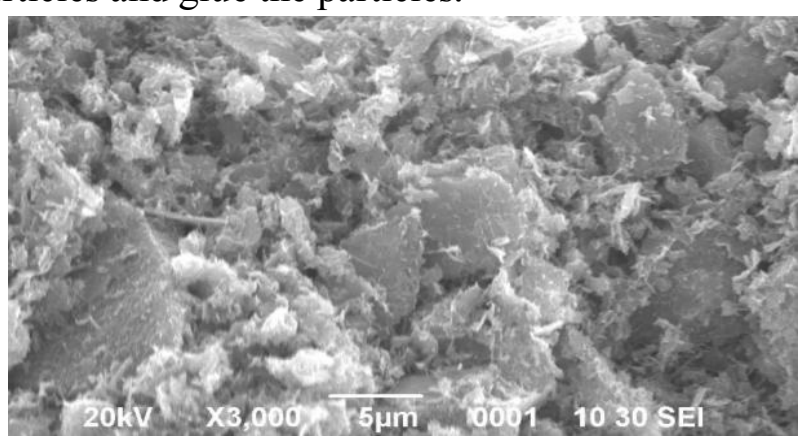

Fig.10 SEM Picture (1.5\% gypsum)

\section{Microstructure Characteristics of Soil Reinforced by Cement-gypsum}

$1.5 \%$ gypsum ,for example, as shown in Fig.10, compared to Fig.8, particles arrange much more regularly and the cluster of particles are bigger. Compared to Fig.9, the difference is the appearance of more bacilliform and fibriform matter. Reasons are as following. The reaction of gypsum and hydrate containing aluminium produce a lot of ettringite and ettringite is acicular crystal that can intertwine and constitute the spatial structure with calcium silicate hydrate, which reduce the average bore diameter to remedy the loss of strength caused by interstice.

\section{Conclusions}

1. Based on $15 \%$ cement, addition lime or gypsum can improve the strength of Nansha soil reinforced by cement. 
2. The best mixing ratio of lime is $3 \%$ around, which means the $20 \%$ of cement weight (the based cement content is $15 \%$ ). Compared to the strength of soil reinforced by $15 \%$ cement merely, the strength increases at a large degree, 28 days UCS for example, it increases by more than $90 \%$.

3. The best content of gypsum is $10 \%$ of the cement weight. Gypsum can improve the early strength of Nansha soil. When the gypsum content is $10 \%, 7$ days UCS increases $92 \%$ compared to the data of soil reinforced by $15 \%$ cement merely and the strength grows much more faster. For a certain strength requirement to Nansha soil, $10 \%$ weight of cement gypsum can reduce the consumption of cement by a approximate rate of $25 \%$.

4. Microscopic structure of soil is one of the important influence factors to its physical and mechanical characters. Nansha soft soil reinforced by different curing agent have different microstructure, so they present different physical and mechanical characters.

\section{References}

[1]Zhou Long-xiang, Tong Hua-wei etc, Study on the engineering properties and the suitable treatment methods of Guangzhou oft oil,J.Journal of Beijing Jiaotong University. 2006,30(1):17-20.

[2]Pan Qin-sheng, Zhang Ke-neng etc, Analysis on the engineering properties of Guangzhou oft oil , J. Geotechnical Engineering World,2005,9(4):46-48.

[3]Yang Zhen-ming,Zeng Wen etc,Experimental research on soft soil foundation reinforced with cement-lime mixed slurry, J. China Water Transport.2010,10(1):194-195,197.

[4]Omar Saeed Baghabra Al-Amoudi etc. Stabilization of an arid, saline sabkha soil using additives, J. Engineering Geology and Hydrogeology, 1995(28): 369-379.

[5]Wang Zhe, Xu Si-fa etc, Study of early strength and shrinkage properties of cement or lime solidified soil, J. Energy Procedia, 16(2012):302-306.

[6]Jia Shanghua, Reinforecment mechanism and Mechanical Properties of lime-cement soil,D. Inner Mongolia Agricultural University, 2011,5:24-36,53.

[7]Huang Xin, Hu Tong'an, Soft soil consolidation by the mixture of industrial waste gypsum and cement, J. Architecture Technology, 2001,(3):161-163.

[8]Zhao Duo-jian, Hao Meng, Geotechnical performance research on reinforcing marine silt using cement and waste gypsum,J. Communications Standardization,2010,11:10-14.

[9]Nurhayat Degirmenci, The using of waste phosphogypsum and natural gypsum in adobe stabilization, J. Construction and Building Materials, 2008(22):1220-1224.

[10]Liu Yi, Huang Xin, Case study of soft soil stabilization with phosphorous gypsum, J. Architecture Technology, 2002,33(3):171-173.

[11]Raymond N. Yong, Vahid R. Ouhadi, Experimental study on instability of bases on naturaland lime/cement-stabilized clayey soils, J. Applied Clay Science, 35(2007)238-249.

[12]Kévin Lemaire etc, Effects of lime and cement treatment on the physicochemical,microstructural and mechanical characteristics of a plastic silt, Engineering Geology, J. 166(2013)255-261.

[13]Huang $\mathrm{Yu}$, Zhou Zi-zhou etc. Micro-experiments on a soft ground improved by cement-mixed soilswith gypsum additive, J. Chinese Journal of Geotechnical Engineering, 2010,32(8):1179-1183.

[14]Ruan Jin-lou, Ruan Bo etc. Experimental study on cement-soil unconfined compressive strength of silty clay, J. Journal of Railway science and engineering, 2009,6(3):56-60. 